\title{
SISTEM INFORMASI MONITORING DAN LAPORAN PROYEK FIBERISASI DI PT. EKSPANINDO PRIMA MULTIMEDIA
}

\author{
Perdana Bagja Kusumah ${ }^{1}$, Puspa Eosina ${ }^{2 *}$, Jejen Jaenudin ${ }^{3}$ \\ Program Studi Teknik Informatika ${ }^{1,2,3}$ \\ Universitas Ibn Khaldun Bogor \\ Jl.KH Sholeh Iskandar Km 2 Kota Bogor \\ pdanakusumah@gmail.com, puspa.eosina@ft.uika-bogor.ac.id, zen@ft.uika-bogor.ac.id
}

\begin{abstract}
Abstrak
PT.Ekspanindo Prima Multimedia merupakan perusahaan yang bergerak di bidang telekomunikasi yang memberikan layanan terpadu di dalam proyek pembangunan jaringan fiber optik di beberapa kota di Indonesia. Untuk mengontrol proyek fiberisasi yang dilakukan memerlukan volume data pekerjaan proyek, mulai dari perencanaan, pelaksanaan, dan akhir proyek. Dalam proses tiga tahapan tersebut data pekerjaan dapat diterapkan ke dalam sistem dengan menggunakan metode pengembangan sistem model linear sequential terdiri dari analisis, desain, implementasi, dan pengujian. Penerapan ilmu sistem informasi pada proses pengolahan data proyek fiberisasi ini adalah (1) menganalisis dan membuat perancangan sistem informasi dengan metode linear sequential yang menghasilkan analisis kebutuhan fungsional, analisis pengguna, dan desain sistem menggunakan UML Diagram, dan di implementasikan menggunakan bahasa komputer. (2) sistem yang di bangun menampilkan informasi berupa daftar volume data perencanaan, pelaksanaan, akhir proyek, dan data selisih untuk dapat memantau pekerjaan proyek fiberisasi yang dibutuhkan oleh PT.Ekspanindo Prima Multimedia.
\end{abstract}

Kata kunci :

Monitoring Proyek, Sistem Linear Sequential, UML

\begin{abstract}
PT.Ekspanindo Prima Multimedia is a company engaged in the telecommunications sector which provides integrated services in fiber optic network development projects in several cities in Indonesia. To control the fiberization project that is carried out requires a volume of project work data, starting from planning, implementation, and the end of the project. In a three-stage process, job data can be applied to
\end{abstract}

the system using the sequential systems model development method consisting of analysis, design, implementation, and testing. The application of information systems science in the data processing of this fiberization project is (1) analyzing and designing an information system with a linear sequential method which results in functional requirements analysis, user analysis, and system design using UML diagrams, and implemented using computer language. (2) the system that is built displays information in the form of a list of the volume of planning data, implementation, end of the project, and the difference data to be able to monitor the work of fiberization projects needed by PT. Ekpanindo Prima Multimedia.

Keywords :

Project Monitoring, Linear sequential Systems, UML.

\section{Pendahuluan}

Teknologi jaringan telekomunikasi dari layanan broadband terus berkembang, dimulai dari generasi pertama atau biasa di sebut dengan istilah $1 \mathrm{G}$ hingga mencapai generasi 4G (Fauzi, Harly, \& Hs, 2012). Saat ini di sebagian belahan dunia sudah memasuki generasi 5G, di Indonesia sendiri teknologi 4G masih belum dapat dinikmati oleh seluruh masyarakat Indonesia, sehingga perusahaan yang menyediakan jasa pelayanan jaringan telekomunikasi memiliki tujuan untuk mengadakan pembangunan jaringan fiberisasi yang menggunakan kabel fiber optik untuk meningkatkan kualitas jaringan dalam rangka memenuhi kebutuhan masyarakat indonesia dalam berkomunikasi.

PT.Eskpanindo Prima Multimedia (Eksprim) adalah perusahaan nasional yang bergerak di bidang telekomunikasi yang memberikan layanan terpadu 
didalam pembangunan jaringan telepon, pembangunan jaringan fiber optik, pembangunan jaringan radio, dan pemeliharaan jaringan telepon dan radio yang berpusat di kota Bandung. PT.Eksprim memiliki beberapa mitra kerja sama dengan pemilik berbagai jenis proyek telekomunikasi, dimana dalam menjalankan proyek memiliki tahapan, mulai dari perencanaan, pelaksanaan, dan tahap akhir proyek. Pada setiap tahapan perusahaan memeliki prosedur yang harus dilakukan, sehingga salah satu masalah yang tengah dihadapi oleh PT.Eksprim adalah monitoring dan laporan proyek yang masih kurang efisien.

Saat ini hampir semua aspek dalam perusahaan baik itu skala kecil, menengah atau besar sudah memanfaatkan dan menggunakan sebuah sistem informasi untuk membantu kegiatan operasionalnya. Mulai dari perusahaan kelas menengah ke bawah hingga perusahaan besar sudah banyak yang menggunakan aplikasi sistem informasi dengan memanfaatkan basis data sehingga dapat mempermudah dalam mengumpulkan, mengeluarkan, memproses, menyimpan, dan mendistribusikan untuk pemanfaatan informasi yang dibutuhkan perusahaan. Sistem informasi yang memanfaatkan basis data, diharapkan setiap proyek dapat lebih mudah mengoptimalkan kegiatan operasional kegiatan dari segi monitoring dan laporan proyek fiberisasi untuk perusahaan. Dengan latar belakang di atas, maka penelitian ini mengangkat judul "Sistem Informasi Monitoring dan Laporan Proyek Fiberisasi Di PT.Ekspanindo Prima Multimedia" yang bertujuan untuk menganalisis dan membangun sistem informasi monitoring dan laporan proyek fiberisasi di PT.Eksprim menggunakan metode pengembangan sistem model linear squential .

\section{Tinjauan Pustaka}

\section{II.1 Sistem Informasi}

Menurut Robert A. Leitch dan K. Roscoe Davis dalam artikel (Ridha, 2018), sistem informasi adalah suatu sistem didalam suatu organisasi yang mempertemukan kebutuhan pengolah transaksi harian, mendukung operasi, bersifat manajerial dan kegiatan strategi dari suatu organisasi dan menyediakan pihak luar tertentu dengan laporanlaporan yang diperlukan. Sistem Informasi dapat didefinisikan sebagai di dalam suatu organisasi yang merupakan kombinasi dari orang-orang, fasilitas, teknologi, media, dan pengendalian yang ditujukan untuk mendapatkan jalur komunikasi penting, memproses tipe transaksi rutin tertentu, memberikan sinyal kepada manajemen dan yang lainnya, terhadap kejadian-kejadian internal dan eksternal yang penting dan menyediakan suatu dasar informasi untuk pengambilan keputusan.

Sistem Informasi adalah sebuah himpunan komponen-komponen yang saling berkaitan yang mengumpulkan, mengeluarkan, memproses, menyimpan, mendistribusikan informasi untuk mendukung pengambilan keputusan dan pengawasan dalam organisasi (Defni, Rahmat, \& Ilahi, 2016).

\section{II.2 Proyek}

Proyek merupakan suatu rangkaian kegiatan dan kejadian yang saling berkaitan untuk mencapai tujuan tertentu dan membuahkan hasil dalam suatu jangka tertentu dengan memanfaatkan sumber daya yang tersedia. Dalam pengertian lain, proyek adalah suatu kegiatan yang mempunyai jangka waktu tertentu dengan sumber daya tertentu pula (Sobirin, 2016).

\section{II.3 Monitoring}

Monitoring adalah proses pengumpulan dan analisis informasi berdasarkan indikator yang ditetapkan secara sistematis dan kontinu tentang program kegiatan sehingga dapat dilakukan Tindakan koreksi untuk penyempurnaan program kegiatan itu selanjutnya. Pemantauan yang dapat dijelaskan sebagai kesadaran (awareness) tentang apa yang ingin diketahui, pemantauan berkadar tingkat tinggi dilakukan agar dapat membuat pengukuran melalui waktu yang menunjukan pergerakan ke arah tujuan atau menjauh dari itu. Monitoring akan memberikan informasi tentang status dan kecenderungan bahwa pengukuran dan evaluasi yang diselesaikan berulang dari waktu ke waktu (Mardiani, 2013).

\section{II.4 Laporan}

Laporan adalah alat komunikasi tertulis yang memuat hasil serta memberikan kesimpulan atau rekomendasi atas fakta-fakta atau keadaan-keadaan yang telah diselidiki sebelumnya (Nuraida, 2008).

\section{II.5 UML}

Unifield Modeling Language merupakan salah satu metode pemodelan visual yang digunakan dalam perancangan dan pembuatan sebuah software yang berorientasikan pada objek. UML merupakan. UML merupakan sebuah standar penulisan atau semacam

Perdana Bagja Kusumah, Puspa Eosina, Jejen Jaenudin 
blue print di mana didalamnya termasuk sebuah bisnis proses, penulisan kelas-kelas dalam sebuah bahasa yang spesifik (Prihandoyo, 2018).

\section{II.6 Pengembangan Sistem}

Pengembangan sistem yang diterapkan mengacu pada model linear sequential (Pressman, 2000) dapat dilihat pada Gambar 1.

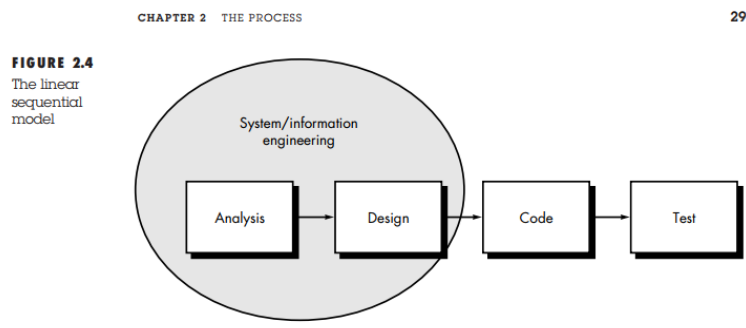

Gambar 1. Linear Squential Model

Dari pengembangan sistem model linear sequential memiliki tahapan mulai dari analisis, desain sistem, kode program atau dengan kata lain adalah implementasi, dan terakhir tahapan pengujian.

\section{a. Analisis}

Pada tahap ini dilakukan proses analisis kebutuhan sistem yang ingin dibuat. Tahap analisis terbagi ke dalam 4 proses di antaranya analisis proses bisnis (analisis proses bisnis yang sedang berjalan dan analisis proses bisnis yang diusulkan), analisis kebutuhan fungsional, analisis pengguna, dan pada penulisan ini akan difokuskan pada bagian analisis sistem dengan UML (Diagram Konteks, Use Case Diagram, Class Diagram).

\section{b. Desain Sistem}

Pada tahapan ini dilakukan proses perancangan desain menggunakan object oriented programming yang digambarkan melalui UML (Activity Diagram, Sequence Diagram, Deployment Diagram, Component Diagram), Perancangan database serta perancangan antar muka dari aplikasi.

\section{c. Implementasi}

Pada tahap ini dilakukan proses implementasi ke dalam kode program menggunakan bahasa pemrograman berbasis web. Proses ini merupakan penerjemah desain ke dalam bahasa yang dikenali oleh komputer.

\section{d. Pengujian Sistem}

Pada tahap ini dilakukan proses pengujian sistem dengan menggunakan metode black box untuk pengujian fungsional dari setiap menu yang dibuat.

\section{METODE PENELITIAN}

\section{III.1 Tempat dan Waktu}

Waktu dilakukannya penelitian ini dimulai pada bulan juni 2019 serta tempat pelaksanaan penelitian dilakukan di PT.Eksprim di Kota Bandung, Jawa Barat, Indonesia.

\section{III.2 Bahan dan Alat}

Bahan penelitian yang digunakan meliputi data rencana, data pelaksanaan, dan data akhir proyek di area Boyolali, Kediri, dan Pekalongan. 
1. Data perencanaan

Tabel 1. Sampel Data Perencanaan

\begin{tabular}{|c|c|c|c|c|c|c|c|c|c|c|c|c|}
\hline \multirow[b]{2}{*}{ No } & \multirow[b]{2}{*}{ Region } & \multirow[b]{2}{*}{ Ring } & \multirow{2}{*}{ Span ID } & \multicolumn{3}{|c|}{ Near End (NE) } & \multicolumn{3}{|c|}{ Far End (FE) } & \multirow{2}{*}{$\begin{array}{c}\text { Tiang } 7 \\
\text { m }\end{array}$} & \multirow{2}{*}{$\underset{\mathrm{m}}{\text { Tiang } 9}$} & \multirow{2}{*}{$\begin{array}{c}\text { Total } \\
\text { Distance (meter) }\end{array}$} \\
\hline & & & & Site ID & $S$ ite Name & $\begin{array}{l}\text { Tower } \\
\text { Owner }\end{array}$ & Site ID & Site Name & $\begin{array}{l}\text { Tower } \\
\text { Owner }\end{array}$ & & & \\
\hline 1 & Boyolali & 1 & BYL01B01 & XXX1775G & SITE B 1_A & $\mathrm{x}$ & XXX2122 & SITE B 1_E & $\mathrm{X}$ & 64 & & 5333 \\
\hline 2 & Boyolali & 2 & BYL02B01 & $\mathrm{XXX} 2122$ & SITE B 2_A & $\mathrm{x}$ & XXX6 & SITE B 2_C & $\mathrm{Y}$ & 40 & & 3243 \\
\hline 3 & Boyolali & 3 & BYL03B01 & XXX6 & SITE B 3_A & $\mathrm{Y}$ & XXXC960 & SITE B 1_D & $\mathrm{Y}$ & 73 & 4 & 6483 \\
\hline 4 & Kediri & 1 & KDR01B01 & XXX1775G9 & SITE K 1_A & Z & XXX2122 & SITE K 1_C & $\mathrm{Y}$ & 55 & & 4.450 \\
\hline 5 & Kediri & 2 & KDR02B01 & XXX2122 & SITE K 2_A & $\mathrm{Y}$ & XXX6 & SITE K 2_C & Z & 29 & 4 & 2650 \\
\hline 6 & Kediri & 3 & PWK03B01 & XXX6 & SITE K 3_A & Z & XXXC960 & SITE K 3_D & $\mathrm{X}$ & 52 & 16 & 5450 \\
\hline 7 & Purwakarta & 1 & PWK01B01 & XXX5 & SITE P 1_A & Z & XXX4546E & SITE P 1_C & $\mathrm{Y}$ & 7 & 4 & 600 \\
\hline 8 & Purwakarta & 2 & PWK02B01 & XXX4546E & SITE P 2_A & $\mathrm{Y}$ & XXX1116E & SITE P 2_D & Y & 11 & 2 & 900 \\
\hline 9 & Purwakarta & 3 & PWK03B01 & XXX1116E & SITE P 3_A & Z & XXX2116 & SITE P 3_E & $\mathrm{X}$ & 34 & & 2750 \\
\hline
\end{tabular}

\section{Data pelaksanaan}

Tabel 2. Sampel Data Pelaksanaan

\begin{tabular}{|c|c|c|c|c|c|c|c|c|}
\hline No & Tanggal & Region & Ring & Span ID & Span Name & Tiang $7 \mathrm{~m}$ & Tiang $9 \mathrm{~m}$ & Total Distance (meter) \\
\hline 1 & 25 Januari 2019 & Boyolali & 1 & BYL01B01 & SITE B 1_A - SITE B 1_E & 69 & & 5.680 \\
\hline 2 & 25 Januari 2019 & Kediri & 1 & KDR01B01 & SITE K 1_A - SITE K 1_C & 49 & & 3.960 \\
\hline 3 & 25 Januari 2019 & Purwakarta & 1 & PWK01B01 & SITE P 1_A - SITE P 1_C & 7 & 2 & 860 \\
\hline 4 & 26 Januari 2019 & Boyolali & 2 & BYL01B02 & SITE B 2_A - SITE B 2_C & 39 & & 3.050 \\
\hline 5 & 26 Januari 2019 & Kediri & 2 & KDR01B02 & SITE K 2_A - SITE K 2_C & 22 & 4 & 2.120 \\
\hline 6 & 26 Januari 2019 & Purwakarta & 2 & PWK01B02 & SITE P 2_A - SITE P 2_D & 9 & 2 & 930 \\
\hline 7 & 27 Januari 2019 & Boyolali & 3 & BYL01B03 & SITE B 3_A - SITE B 3_D & 71 & 6 & 6.600 \\
\hline 9 & 27 Januari 2019 & Purwakarta & 3 & PWK01B03 & SITE P 3_A - SITE P 3_E & 39 & & 3.120 \\
\hline
\end{tabular}

Perdana Bagja Kusumah, Puspa Eosina, Jejen Jaenudin 


\section{Data akhir}

Tabel 3. Sampel Data Akhir

\begin{tabular}{|c|c|c|c|c|c|c|c|}
\hline No & Region & Ring & Span ID & Span Name & Tiang $7 \mathrm{~m}$ & Tiang $9 \mathrm{~m}$ & Total Distance (meter) \\
\hline 1 & Boyolali & 1 & BYL01B01 & SITE B 1_A - SITE B 1_E & 69 & & 5.623 \\
\hline 2 & Boyolali & 2 & BYL02B01 & SITE B 2_A - SITE B 2_C & 40 & 2 & 3.022 \\
\hline 3 & Boyolali & 3 & BYL03B01 & SITE B 3_A - SITE B 3_D & 71 & 4 & 6.586 \\
\hline 4 & Keidiri & 1 & KDR01B01 & SITE K 1_A - SITE K 1_C & 49 & & 3.905 \\
\hline 5 & Keidiri & 2 & KDR02B01 & SITE K 2_A - SITE K 2_C & 22 & 4 & 2.105 \\
\hline 6 & Keidiri & 3 & PWK03B01 & SITE K 3_A - SITE K 3_D & 43 & 12 & 4.621 \\
\hline 7 & Pekalongan & 1 & PWK01B01 & SITE P 1_A - SITE P 1_C & 6 & 2 & 847 \\
\hline 8 & Pekalongan & 3 & PWK03B01 & SITE P 3_A - SITE P 3_E & 38 & 4 & 3.111 \\
\hline
\end{tabular}

Alat yang digunakan untuk penelitian terdiri dari perangkat keras (hardware) dan perangkat lunak (software), yang dispesifikasikan pada tabel berikut.

Tabel 4. Spesifikasi Perangkat Keras

\begin{tabular}{|c|c|c|}
\hline No & Jenis & Spesifikasi \\
\hline 1 & Notebook & HP 15-bw0xx \\
\hline 2 & Prosessor & $\begin{array}{c}\text { AMD A10-9620P } \\
\text { RADEON R5 }\end{array}$ \\
\hline 3 & Ram & $8 \mathrm{~GB}$ \\
\hline 4 & Hdd & $1 \mathrm{~TB}$ \\
\hline 5 & Modem & Fiber Home \\
\hline 6 & Printer & HP Deskjet 2060 \\
\hline
\end{tabular}

Tabel 5. Spesifikasi Perangkat Lunak

\begin{tabular}{|c|c|c|}
\hline No & Jenis & Spesifikasi \\
\hline 1 & Sistem Operasi & Windows 10 \\
\hline 2 & Browser & Google Chrome \\
\hline 3 & Text Prosessing & Ms Office 365 \\
\hline 4 & Tools UML & Visio 2013 \\
\hline
\end{tabular}

\section{III.3 Metode Penelitian}

Dalam penyusunan penulisan ini menggunakan metode penelitian meliputi, metode pengumpulan data seperti observasi, wawancara, dan studi pustaka. Adapun metode pengembangan sistem yang akan digunakan dalam pembuatan sistem ini adalah metode pengembangan model linear sequential. Metode ini memiliki langkah-langkah yang tersusun secara terurut dimulai dari tahap analisis, desain, implementasi, dan pengujian. Maka dibuatlah alur rancangan penelitian yang dapat dilihat pada Gambar 2. 


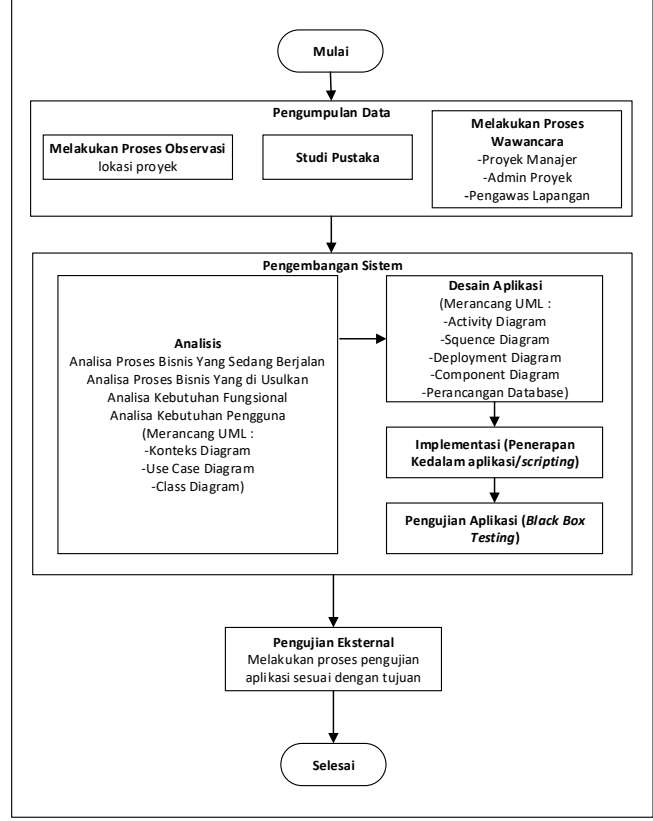

Gambar 2. Model Penelitian

\section{HASIL DAN PEMBAHASAN}

\section{IV.1 Analisis Data Penelitian}

1. Data hasil pengolahan

Adapun hasil pengolahan data penelitian yang didapat meliputi data total perencanaan, data total laporan pelaksanaan, dan data total akhir proyek di setiap area.

\section{Tabel 6. Pelabelan Data}

\begin{tabular}{|c|c|c|}
\hline No & Data & Pelabelan \\
\hline 1 & $\begin{array}{c}\text { Total data perencanaan per } \\
\text { area proyek }\end{array}$ & A \\
\hline 2 & $\begin{array}{c}\text { Total data pelaksanaan per } \\
\text { area proyek }\end{array}$ & B \\
\hline 3 & $\begin{array}{c}\text { Total data akhir per area } \\
\text { proyek }\end{array}$ & $\mathrm{C}$ \\
\hline
\end{tabular}

Tabel 7. Data Total Perencanaan per Area (A)

\begin{tabular}{|c|c|c|c|c|c|}
\hline No & Area & $\begin{array}{c}\text { Total } \\
\text { Ring }\end{array}$ & $\begin{array}{c}\text { Tiang 7 } \\
\mathbf{m}\end{array}$ & $\begin{array}{c}\text { Tiang 9 } \\
\mathbf{m}\end{array}$ & $\begin{array}{c}\text { Total Distance } \\
\text { (meter) }\end{array}$ \\
\hline 1 & Boyolali & 3 & 177 & 4 & 15.059 \\
\hline 2 & Keidiri & 3 & 136 & 20 & 12.550 \\
\hline 3 & Pekalongan & 3 & 52 & 6 & 4.250 \\
\hline
\end{tabular}

Tabel 8. Data Total Pelaksanaan per Area (B)

\begin{tabular}{|c|c|c|c|c|c|}
\hline No & Region & $\begin{array}{c}\text { Total } \\
\text { Ring }\end{array}$ & $\begin{array}{c}\text { Tiang 7 } \\
\mathbf{m}\end{array}$ & $\begin{array}{c}\text { Tiang 9 } \\
\mathbf{m}\end{array}$ & $\begin{array}{c}\text { Total Distance } \\
\text { (meter) }\end{array}$ \\
\hline 1 & Boyolali & 3 & 179 & 6 & 15.330 \\
\hline 2 & Keidiri & 3 & 112 & 18 & 10.710 \\
\hline 3 & Pekalongan & 3 & 55 & 4 & 41.547 \\
\hline
\end{tabular}

Tabel 9. Data Total Akhir per Area (C)

\begin{tabular}{|c|c|c|c|c|c|}
\hline No & Area & $\begin{array}{c}\text { Total } \\
\text { Ring }\end{array}$ & $\begin{array}{c}\text { Tiang 7 } \\
\mathbf{m}\end{array}$ & $\begin{array}{c}\text { Tiang 9 } \\
\mathbf{m}\end{array}$ & $\begin{array}{c}\text { Total Distance } \\
\text { (meter) }\end{array}$ \\
\hline 1 & Boyolali & 3 & 180 & 6 & 15.231 \\
\hline 2 & Keidiri & 3 & 114 & 16 & 10.631 \\
\hline 3 & Pekalongan & 3 & 53 & 8 & 4.883 \\
\hline
\end{tabular}

\section{Perhitungan data selisih}

Perhitungan data selisih yang dibutuhkan didalam penelitian akan dilakukan secara otomatis didalam sistem setelah ketiga data di input ke dalam database oleh masing-masing pengguna atau divisi, hasil dari perhitungan akan mengetahui selisih mulai dari perencanaan, pelaksanaan, dan akhir proyek.

Tabel 10. Perhitungan Data Selisih

\begin{tabular}{|c|c|c|}
\hline No & Perhitungan & Hasil \\
\hline 1 & A - B & AB \\
\hline 2 & A - C & AC \\
\hline
\end{tabular}


Tabel 11. Data Selisih Area Boyolali

\begin{tabular}{|c|c|c|c|c|c|c|}
\hline No & Area & $\begin{array}{c}\text { Perenc } \\
\text { anaan }\end{array}$ & $\begin{array}{c}\text { Pelaksa } \\
\text { naan }\end{array}$ & Akhir & $\begin{array}{c}\text { Perencana } \\
\text { an-Akhir } \\
\text { (A-C) }\end{array}$ & $\begin{array}{c}\text { Pelaksana } \\
\text { an-Akhir } \\
\text { (B-C) }\end{array}$ \\
\hline 1 & $\begin{array}{c}\text { Total } \\
\text { Distance } \\
\text { (meter) }\end{array}$ & 15.059 & 15.330 & 15.231 & -172 & 99 \\
\hline 2 & $\begin{array}{c}\text { Tiang } \\
7 \mathrm{~m}\end{array}$ & 177 & 179 & 180 & -3 & -1 \\
\hline 3 & $\begin{array}{c}\text { Tiang } \\
9 \mathrm{~m}\end{array}$ & 6 & 4 & 6 & 0 & -2 \\
\hline
\end{tabular}

\section{IV.2 Analisis Pengguna}

Berdasarkan analisis pengguna pada penelitian yang dilakukan di PT.Eksprim di fokuskan pada divisi pengawas lapangan, admin proyek, dan proyek manajer. Rincian analisis pengguna pada penelitian ini dapat diliat pada tabel berikut.

Tabel 12. Analisis Pengguna

\begin{tabular}{|c|c|c|}
\hline No & Pengguna & Keterangan \\
\hline 1 & $\begin{array}{c}\text { Pengawas } \\
\text { Lapangan }\end{array}$ & $\begin{array}{c}\text { Mengelola data } \\
\text { pelaksanaan proyek }\end{array}$ \\
\hline 2 & Admin Proyek & $\begin{array}{c}\text { Mengelola data } \\
\text { perencanaan, data span, } \\
\text { data site, data kabel, dan } \\
\text { data akhir proyek }\end{array}$ \\
\hline 3 & Proyek Manajer & $\begin{array}{c}\text { Memonitoring hasil } \\
\text { proses dari data } \\
\text { dan data akhir proyek } \\
\text { serta melihat data selisih }\end{array}$ \\
\hline
\end{tabular}

\section{IV.3 Analisis Proses Bisnis Yang di Usulkan}

Proses bisnis yang diusulkan adalah proses binis yang di kembangkan berkaitan dengan sistem aplikasi diperoleh dari proses bisnis yang berjalan pada proyek fiberisasi di perusahaan. Proses bisnis yang diusulkan dapat dilihat pada Gambar 3.

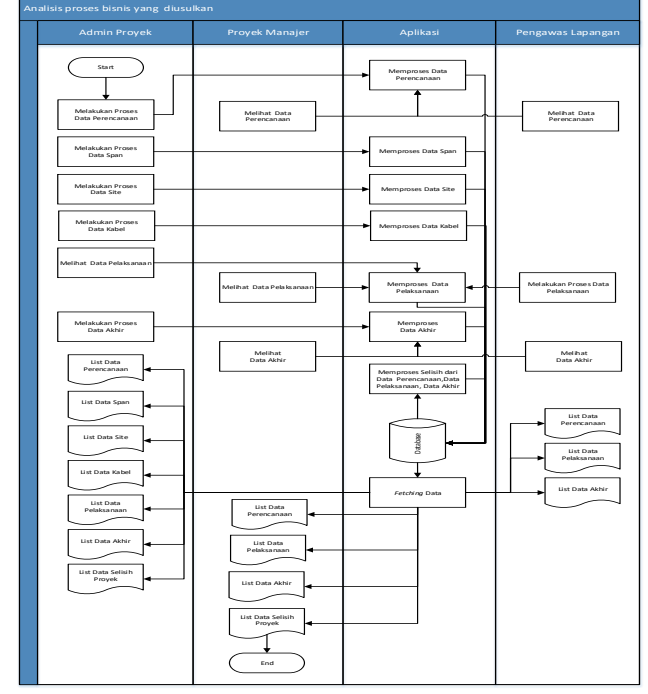

Gambar 3. Proses Bisnis Yang di Usulkan

\section{IV.4 Diagram Konteks}

Konteks diagram merupakan diagram yang menggambarkan proses bisnis terhadap suatu sistem yang dibuat. Proses bisnis mendefinisikan kegiatan pelaku (actor) terhadap sistem. Konteks diagram dapat dilihat pada Gambar 4.

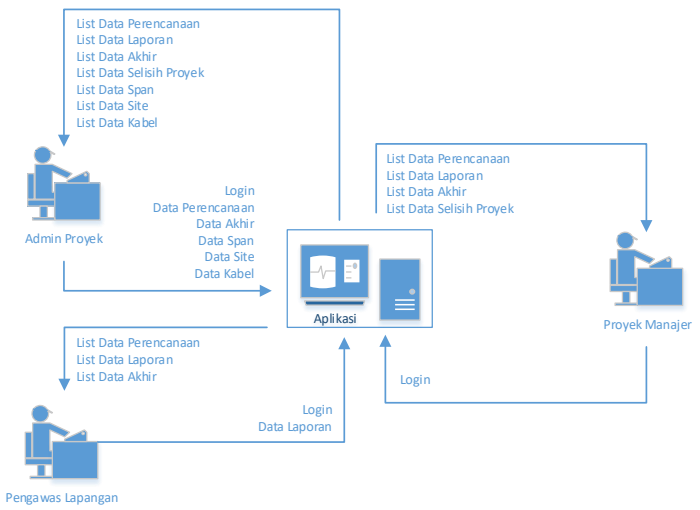

Gambar 4. Konteks Diagram

\section{IV.5 Use Case Diagram}

Use case Diagram adalah gambaran grafis dari beberapa atau semua aktor, use case, dan interaksi di antaranya yang memperkenalkan suatu sistem. Use case memberikan gambaran singkat hubungan antara use case, actor, dan sistem. Diagram use case yang diterapkan menggunakan referensi Software Engineering A Practitioner's Approach Seventh Edition Roger S.Pressman (Pressman, 2010). Use case ini untuk mengetahui fungsi-fungsi ada pada 
sistem monitoring dan laporan fiberisasi, dapat dilihat pada Gambar 5.

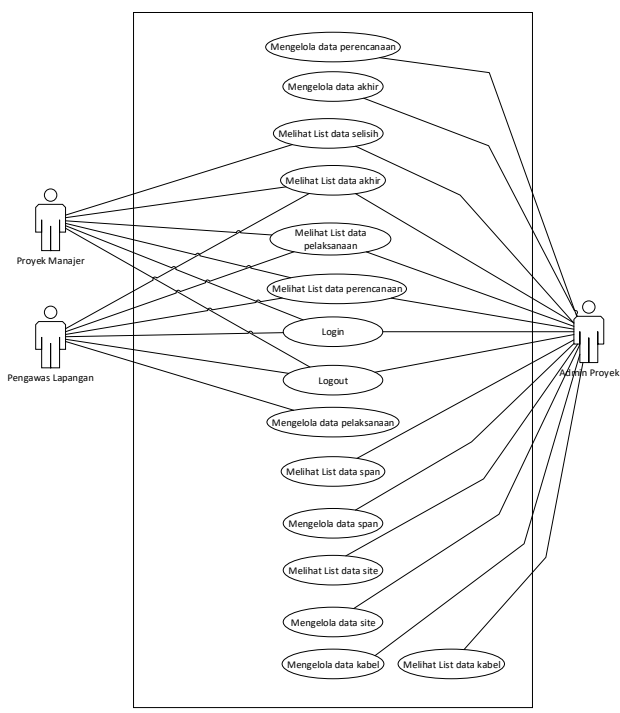

Gambar 5. Use Case Diagram

\section{IV.6 Class Diagram}

Class diagram merupakan sebuah spesifikasi yang jika di instansiasi akan menghasilkan sebuah objek dan merupakan inti dari pengembangan dan desain berorientasi objek. Class diagram menggambarkan atribut suatu sistem, sekaligus menawarkan layanan untuk memanipulasi keadaan tersebut (metode/fungsi). Untuk lebih jelasnya dapat dilihat pada Gambar 6.

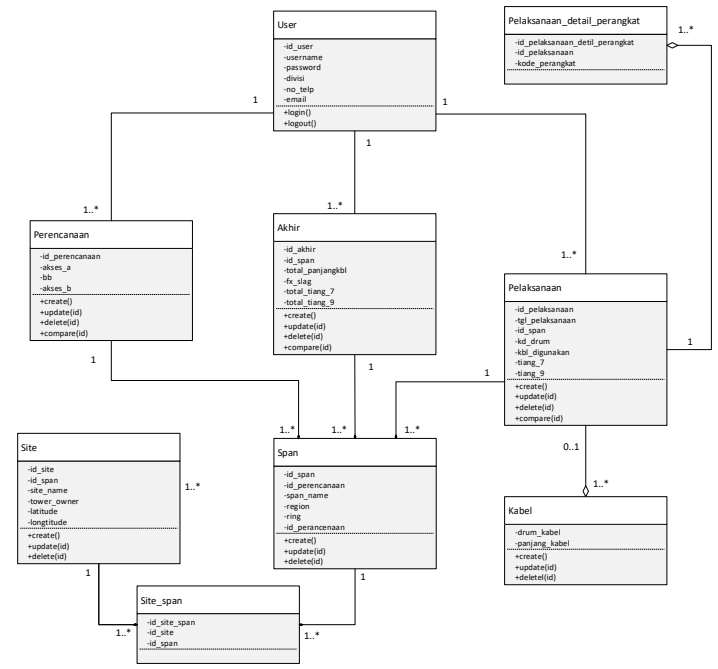

Gambar 6. Class Diagram

\section{KESIMPULAN DAN SARAN}

\section{V.1 Kesimpulan}

Berdasarkan hasil dan pembahasan, maka dapat ditarik kesimpulan sebagai berikut :

1. Perancangan Sistem Informasi Monitoring dan Laporan Proyek Fiberisasi yang dikerjakan di PT.Eksprim telah dilakukan penelitian dan perancangan untuk pembuatan sistem informasi menggunakan metode linear sequential dengan tahapan analisis yaitu berupa analisis data penelitian serta perhitungan data selisih, anilisis pengguna, dan analisis proses bisnis yang diusulkan. Pada tahapan desain menggunakan $U M L$ Diagram seperti Diagram Konteks, Use Case Diagram, Class Diagram.

2. Hasil dari proses data fiberisasi yang didapat bisa mengetahui berapa volume selisih dari perencanaan dengan data akhir, dan pada saat pelaksanaan memiliki selisih dengan data akhir karena peluang terjadinya kesalahan pelaporan di lapangan yang nantinya bisa di monitoring oleh divisi proyek manajer.

\section{V.2 Saran}

"Sistem Informasi Monitoring dan Laporan Proyek Fiberisasi Di PT.Ekspanindo Prima Multimedia" saat ini masih berupa output di setiap data melakukan perhitungan total dan menghitung selisih dari data-data yang sudah di input oleh masing-masing pengguna, sehingga masih dapat di kembangkan, yaitu dengan pengambilan keputusan dari hasil selisih yang didapat, menghitung berapa harga yang bisa ditagih dari proyek yang sudah dikerjakan, melengkapi dokumentasi foto, lokas beserta titik koordinat, data KMZ, dan data lain yang bersangkutan.

\section{REFERENSI}

Fauzi, A., Harly, G. S., \& Hs, H. (2012). Analisis Penerapan Teknologi Jaringan LTE 4G di Indonesia. Manajemen, Volume 10. Retrieved November 27, 2020,

https://jurnal.unikom.ac.id/jurnal/analisispenerapan-teknologi.2x

Perdana Bagja Kusumah, Puspa Eosina, Jejen Jaenudin 
Ridha, M. R. (2018). Perancangan Sistem Infomasi Pengolahan Data Kuliah Kerja Usaha dan Penelitian (Studi Kasus: Program Studi Sistem Informasi Universitas Islam Indragiri). SISTEMASI, 2(4), 14-26.

http://sistemasi.ftik.unisi.ac.id/index.php/stm si/article/download/137/44

Defni, D., Rahmat, R., \& Ilahi, R. R. (2016). Rancang Bangun Sistem Informasi Berbasis Web Pada Dinas Pertanian Kota Padang. Jurnal Momentum, 18(1). Retrieved October 29, 2019.

https://ejournal.itp.ac.id/index.php/momentu $\mathrm{m} /$ article/view/383

Sobirin, M. (2016). Kinerja Proyek Konstruksi Bangunan Gedung di Pengaruhi Oleh Beberapa Faktor Seperti Sumber Daya Manusia , Sumber Daya Alat Dan Sumber Daya Material, 16.

http://www.daringtridarmauniversitastamaja gakarsa.ac.id/wpcontent/uploads/2016/12/6_HM.Sobirin_Vol _XI-No_2.pdf

Mardiani, G. T. (2013). Sistem Monitoring Data Aset Dan Inventaris PT Telkom Cianjur Berbasis Web. Komputa: Jurnal Ilmiah Komputer dan Informatika, 2(1). Retrieved November 14, 2020.

https://ojs.unikom.ac.id/index.php/komputa/a rticle/view/78

Ida, Nuraida. 2008. Manajemen Administrasi Perkantoran. Yogyakarta: Kanisius.

Prihandoyo, M. T. (2018). Unified Modeling Language (UML) Model Untuk Pengembangan Sistem Informasi Akademik Berbasis Web. Jurnal Informatika: Jurnal Pengembangan IT, 3(1), 126-129.

http://ejournal.poltektegal.ac.id/index.php/inf ormatika/article/view/765

Pressman, R. S. (2000). Software engineering: A practitioner's approach. McGraw-Hill series in computer science (5th ed.). Boston, Mass: McGraw Hill.

Perdana Bagja Kusumah, Puspa Eosina, Jejen Jaenudin 